\title{
Sexual dimorphism in cuticular hydrocarbons of the Australian field cricket Teleogryllus oceanicus (Orthoptera: Gryllidae)
}

\author{
Melissa L. Thomas*, Leigh W. Simmons \\ Centre for Evolutionary Biology, School of Animal Biology, The University of Western Australia, Australia
}

\section{A R T I C L E I N F O}

Article history:

Received 11 March 2008

Received in revised form

10 April 2008

Accepted 15 April 2008

Keywords:

Cuticular hydrocarbons

Sexual dimorphism

Sexual selection

Teleogryllus oceanicus

\begin{abstract}
A B S T R A C T
Sexual dimorphism is presumed to reflect adaptive divergence in response to selection favouring different optimal character states in the two sexes. Here, we analyse patterns of sexual dimorphism in the cuticular hydrocarbons of the Australian field cricket Teleogryllus oceanicus using gas chromatography. Ten of the 25 peaks found in our chromatographs, differed in their relative abundance between the sexes. The presence of sexual dimorphism in T. oceanicus is discussed in reference to a review of sexual dimorphism in cuticular hydrocarbons of other insects. We found that this trait has been examined in 103 species across seven different orders. Seventy-six of these species (73\%) displayed sex specificity of cuticular hydrocarbons, the presence/absence of which does not appear to be directly linked to phylogeny. The occurrence of sexual dimorphism in cuticular hydrocarbons of some but not other species, and the extent of variation within genera, suggest that this divergence has been driven primarily by sexual selection.
\end{abstract}

Crown Copyright $\odot 2008$ Published by Elsevier Ltd. All rights reserved.

\section{Introduction}

Hydrocarbons are major constituents of cuticular waxes that are found on the exoskeleton of most insects. While the primary function of these compounds has been identified as providing water-proofing and protection against environmental stresses, it is now well recognized that cuticular hydrocarbons also play a central role in insect communication (Howard and Blomquist, 2005). Interspecifically, cuticular hydrocarbons have been shown to function in species recognition, and predator deterrence or avoidance (Hoffmann et al., 2006). Intraspecifically, cuticular hydrocarbons are known to function in social communication and short-range sexual communication, facilitating recognition of sexual partners, and in some cases acting as a courtship inhibitor to reduce the attractiveness of mated females (Ferveur, 2005; Howard and Blomquist, 2005).

In field crickets, mate choice is composed of several distinct elements, including contact chemoreception. Although males generally attract females over long distances by singing, once individuals are in close contact, chemical signals, or cuticular hydrocarbons, can play a central role in mate selection. For example, chemosensory cues enable female crickets to preferentially mate with novel males (Ivy et al., 2005), to favour unrelated males (Simmons, 1991), and choose dominant males over

\footnotetext{
* Corresponding author. Tel.: +61 86488 2239; fax: +61 864881029.

E-mail address: mlthomas@cyllene.uwa.edu.au (M.L. Thomas).
}

subordinates (Kortet and Hedrick, 2005). Although mate choice experiments in crickets focus primarily on female choice, male crickets can also discriminate between females using chemosensory cues. For example, males of the Australian field cricket, Teleogryllus oceanicus, are known to display prudent ejaculate allocation in response to a female's mating status (Thomas and Simmons, 2007), and this discrimination could be based on chemical signals transferred from males to females during mating.

Sexual dimorphism of cuticular hydrocarbons has been previously found in a number of species of Orthopterans; however, not all the Orthopterans studied display this trait (Appendix). Here, we examine patterns of variation in cuticular composition between genders of $T$. oceanicus to determine if, and how this species cuticular composition varies between the sexes. We use quantitative analyses of gas chromatography profiles to compare individuals of the same age but different sex. As many insect species are sexually dimorphic for cuticular composition, we discuss our results in reference to a review of this literature. In particular, we focus our discussion on the evolutionary processes that may have led to divergence between the sexes in T. oceanicus, and other insect taxa.

\section{Materials and methods}

The parental generation of experimental crickets was the offspring derived from individuals collected from a banana plantation in Carnarvon, northwestern Australia. Newly hatched 
first generation nymphs were raised in $5 \mathrm{~L}$ plastic containers with 30 full siblings. Sexes were separated before the adult moult. After adult eclosion, crickets were isolated in individual boxes $(7 \times 7 \times 5 \mathrm{~cm})$ for $14 \pm 3$ days until sexually mature, before their cuticular hydrocarbons were extracted. All crickets had access to cat chow and water ad libitum, and were kept in a constant temperature room, at $25^{\circ} \mathrm{C}$ with a $12: 12 \mathrm{~h}$ light-dark cycle.

To quantify cuticular hydrocarbons, we immersed freshly freeze-killed individual crickets in $4 \mathrm{ml}$ of hexane for $5 \mathrm{~min}$. We injected $1 \mu \mathrm{L}$ of this sample into a gas chromatograph and mass spectrometer (Shimadzu GCMS QP2010) operating in the split mode (ratio 10:1), and fitted with a Stabilwax column of $30 \times 0.25 \mathrm{~mm}$ internal diameter (i.d.) using helium as a carrier gas (total flow rate of $13.2 \mathrm{~mL} / \mathrm{min}$ ). We optimized separation of the extract by using a column temperature profile in which the analysis began at a temperature of $50{ }^{\circ} \mathrm{C}$ for $1 \mathrm{~min}$, and rose to $250{ }^{\circ} \mathrm{C}$ for $20 \mathrm{~min}$. The transfer line from the GC to the mass spectrometer was set at $250^{\circ} \mathrm{C}$. We analysed washes derived from 28 unmated males and 26 unmated females.

We also analysed washes from an additional 10 crickets (five males and five females) on an RTX-5MS column $(30 \times 0.25 \mathrm{~mm}$ i.d.) using the same gas chromatograph and mass spectrometer. This is because the Stabilwax column used in the analysis described earlier has a maximum temperature of $260^{\circ} \mathrm{C}$; a temperature not high enough to determine if there are hydrocarbons in the C36-C40+ range. We optimized separation of these extracts using a column temperature profile that began at $50{ }^{\circ} \mathrm{C}$ for $1 \mathrm{~min}$, rose to $250^{\circ} \mathrm{C}$ for $20 \mathrm{~min}$ and rose again to $320^{\circ} \mathrm{C}$ for $10 \mathrm{~min}$. We again used helium as the carrier gas (total flow rate $11.5 \mathrm{~mL} / \mathrm{min}$ ).

For data analysis, peaks were labelled by peak number, which corresponded to their retention times (Fig. 1, Table 1). Individual hydrocarbons were identified using a custom GCMS library based on authentic standards, NIST library and other published data (Blomquist et al., 1976). For data analysis, we used proportional peaks, because absolute peaks are often subject to large experimental errors (Blows and Allan, 1998; Rundle et al., 2005; Savarit and Ferveur, 2002). Proportional peaks were calculated by dividing the area of each peak in a given sample by the sum of all peak areas in that sample. We used a log contrast transformation to remove the problem of non-independence introduced into the analysis by using proportions (Blows and Allan, 1998; Rundle et al., 2005; Simmons et al., 2003). Log contrasts were calculated by dividing an arbitrarily chosen peak (peak 5 ) by the proportional peak area, and then taking the $\log$ of the new variables. $\log (1+x)$ was used because not all individuals contained every compound. We performed a principal components analysis on these new variables following Neems and Butlin (1995).

\section{Results}

Using the Stabilwax column, we were able to distinguish 25 peaks that ranged in chain length from 29 to 35 carbons (Table 1 ). The RTX-5MS column yielded no additional peaks. The samples run on this column are excluded from the following analysis.

The principal component analysis returned 24 components. We considered only those components where the eigenvalue was greater than 1 (Norman and Streiner, 1994) in the multivariate data set. Five components had an eigenvalue greater than 1 , and collectively explained $83 \%$ of the variance in cuticular hydrocarbon blends. The percentage of variance explained was 39.95, 22.36, 9.68, 5.77 and 5.01 for components 1-5, respectively.

Univariate analysis of variance of the individual peaks revealed that principal component one (PC1) showed significant differences between the sexes (Table 2, Fig. 2). To examine the relative contribution of each peak, we used correlations between the original variables and the PC scores (Table 3). Cuticular hydrocarbons with correlations greater than 0.7 times the largest correlation were considered to have contributed significantly to the PC (Mardia et al., 1979). Ten peaks were found to contribute to PC1. Examination of the raw concentrations of these 10 peaks show that the strongest component was peak 22 representing $32 \%$ of the total cuticular hydrocarbons present on males, but only $24 \%$ of the total cuticular hydrocarbons present on females (Table 1).
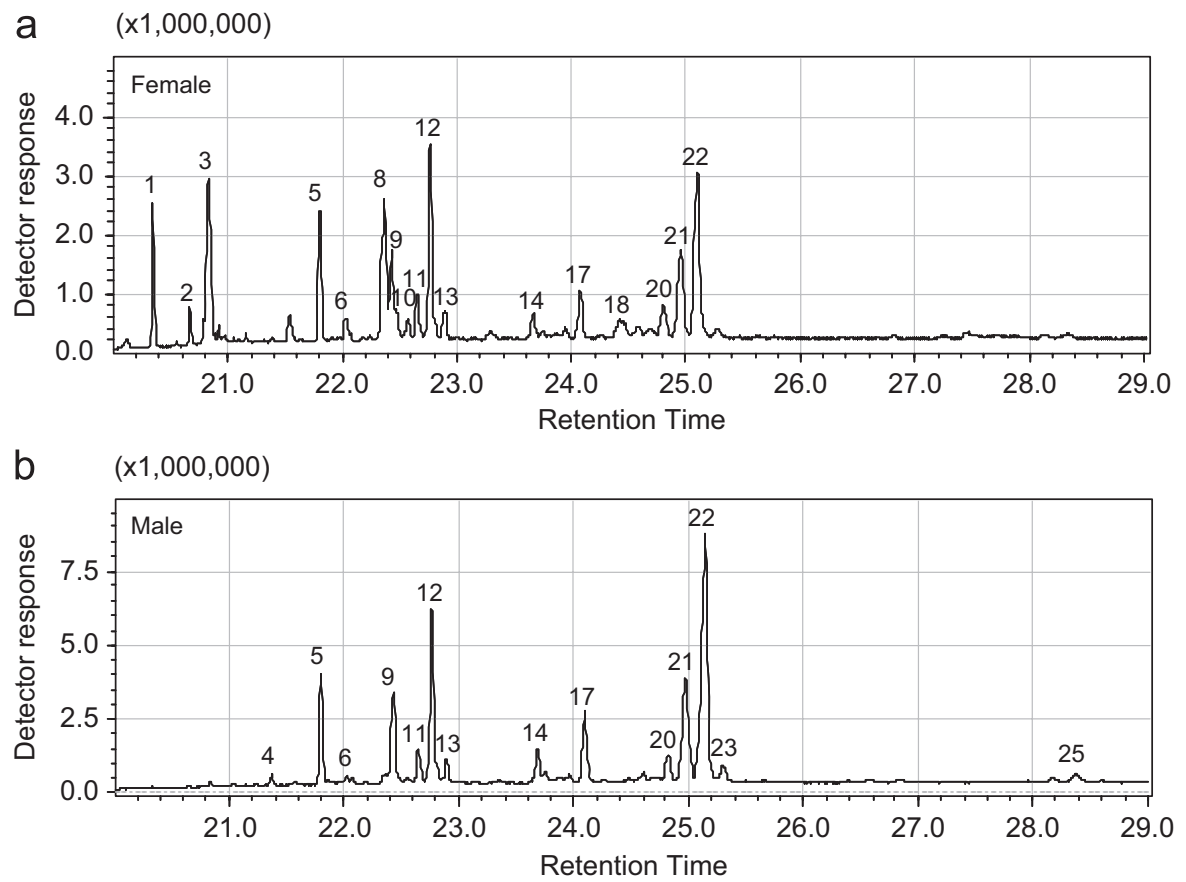

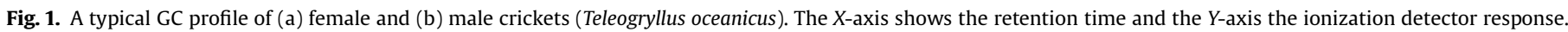
The figures have different values on the $Y$-axes. Peak numbers are indicated (see Table 1 for more detail). Note not all peaks were found in every cricket. 
Table 1

The relative contribution of the 25 cuticular hydrocarbon peaks identified from hexane washes of male and female $T$. oceanicus

\begin{tabular}{|c|c|c|c|c|c|}
\hline \multirow[t]{2}{*}{ Peak } & \multirow[t]{2}{*}{ Retention time } & \multirow[t]{2}{*}{ Molecular weight } & \multirow[t]{2}{*}{ Hydrocarbon } & \multicolumn{2}{|c|}{ Concentration $(\% \pm$ S.E. $)$} \\
\hline & & & & Male & Female \\
\hline 1 & 20.33 & & Unresolved & $0.000 \pm 0.358$ & $1.267 \pm 0.372$ \\
\hline 2 & 20.66 & 408 & $\mathrm{C}_{29}$ & $0.000 \pm 0.119$ & $0.409 \pm 0.124$ \\
\hline 3 & 20.84 & 406 & $\mathrm{C}_{29: 1}$ & $0.109 \pm 0.602$ & $1.807 \pm 0.625$ \\
\hline 4 & 21.37 & & Unresolved & $0.660 \pm 0.066$ & $0.225 \pm 0.069$ \\
\hline 5 & 21.80 & 436 & $\mathrm{x}-\mathrm{meC}_{31}$ & $6.617 \pm 0.431$ & $9.841 \pm 0.448$ \\
\hline 6 & 22.02 & & Unresolved & $0.543 \pm 0.078$ & $0.771 \pm 0.081$ \\
\hline 7 & 22.08 & 434 & $\mathrm{C}_{31: 1}$ & $0.286 \pm 0.035$ & $0.048 \pm 0.037$ \\
\hline 8 & 22.34 & 434 & $C_{31: 1}$ & $0.966 \pm 0.866$ & $5.78 \pm 0.898$ \\
\hline 9 & 22.43 & 434 & $\mathrm{C}_{31: 1}$ & $7.638 \pm 0.577$ & $4.648 \pm 0.599$ \\
\hline 10 & 22.55 & 432 & $C_{31: 2}$ & $0.249 \pm 0.112$ & $0.341 \pm 0.116$ \\
\hline 11 & 22.65 & 432 & $C_{31: 2}$ & $2.906 \pm 0.175$ & $1.859 \pm 0.181$ \\
\hline 12 & 22.77 & 432 & $C_{31: 2}$ & $15.851 \pm 0.812$ & $9.197 \pm 0.843$ \\
\hline 13 & 22.89 & 432 & $C_{31: 2}$ & $2.252 \pm 0.180$ & $0.783 \pm 0.187$ \\
\hline 14 & 23.68 & 464 & $\mathrm{x}-\mathrm{meC}_{33}$ & $2.541 \pm 0.931$ & $9.091 \pm 0.966$ \\
\hline 15 & 23.75 & & Unresolved & $0.209 \pm 0.051$ & $0.082 \pm 0.052$ \\
\hline 16 & 23.95 & 462 & $C_{33: 1}$ & $0.670 \pm 0.491$ & $5.046 \pm 0.509$ \\
\hline 17 & 24.09 & 462 & $C_{33: 1}$ & $6.509 \pm 0.381$ & $1.764 \pm 0.396$ \\
\hline 18 & 24.42 & 462 & $C_{33: 1}$ & $0.000 \pm 0.275$ & $1.493 \pm 0.286$ \\
\hline 19 & 24.60 & 462 & $C_{33: 1}$ & $0.649 \pm 0.064$ & $0.085 \pm 0.067$ \\
\hline 20 & 24.82 & 460 & $C_{33: 2}$ & $2.476 \pm 0.174$ & $2.100 \pm 0.181$ \\
\hline 21 & 24.96 & 460 & $C_{33: 2}$ & $13.326 \pm 0.525$ & $12.570 \pm 0.545$ \\
\hline 22 & 25.14 & 460 & $C_{33: 2}$ & $32.669 \pm 1.153$ & $24.019 \pm 1.197$ \\
\hline 23 & 25.29 & 460 & $C_{33: 2}$ & $2.132 \pm 0.175$ & $1.054 \pm 0.181$ \\
\hline 24 & 27.19 & 492 & $C_{35}$ & $0.000 \pm 0.724$ & $2.736 \pm 0.752$ \\
\hline 25 & 28.36 & 488 & $C_{35: 2}$ & $0.740 \pm 0.660$ & $2.981 \pm 0.685$ \\
\hline
\end{tabular}

Table 2

Univariate ANOVAs using the principal component scores of the five components with eigenvalues greater than 1 (PC1-5)

\begin{tabular}{|c|c|c|c|c|}
\hline Component & d.f. & SS & $F$ & $p$ \\
\hline \multicolumn{5}{|l|}{ PC1 } \\
\hline Model & 1 & 359.11 & 125.34 & $<0.001$ \\
\hline Error & 52 & 148.99 & & \\
\hline \multicolumn{5}{|l|}{ PC2 } \\
\hline Model & 1 & 0.15 & 0.03 & 0.87 \\
\hline Error & 52 & 284.28 & & \\
\hline \multicolumn{5}{|l|}{ PC3 } \\
\hline Model & 1 & 1.23 & 0.52 & 0.47 \\
\hline Error & 52 & 121.93 & & \\
\hline \multicolumn{5}{|l|}{ PC4 } \\
\hline Model & 1 & 0.01 & 0.003 & 0.95 \\
\hline Error & 52 & 73.33 & & \\
\hline \multicolumn{5}{|l|}{ PC5 } \\
\hline Model & 1 & 0.71 & 0.59 & 0.45 \\
\hline Error & 52 & 63.02 & & \\
\hline
\end{tabular}

Significant value is in bold.

\section{Discussion}

Consistent with previous research in insects (Fig. 3, Appendix), our result demonstrates sexual dimorphism in the cuticular hydrocarbon profiles of $T$. oceanicus. In our multivariate analysis, 10 of the 25 peaks were found to differ between the genders in their relative concentrations (Table 3 ). Although the functional significance of this sexual dimorphism in $T$. oceanicus remains to be tested, our result suggests that it is a blend of cuticular compounds, rather than a single compound, which would be important for sex discrimination, as is the case in the cricket Gryllus bimaculatus (Tregenza and Wedell, 1997).

While we found gender specific differences in cuticular hydrocarbons in T. oceanicus, not all Orthopterans display this trait (Fig. 3). In fact, little or no gender differences in cuticular

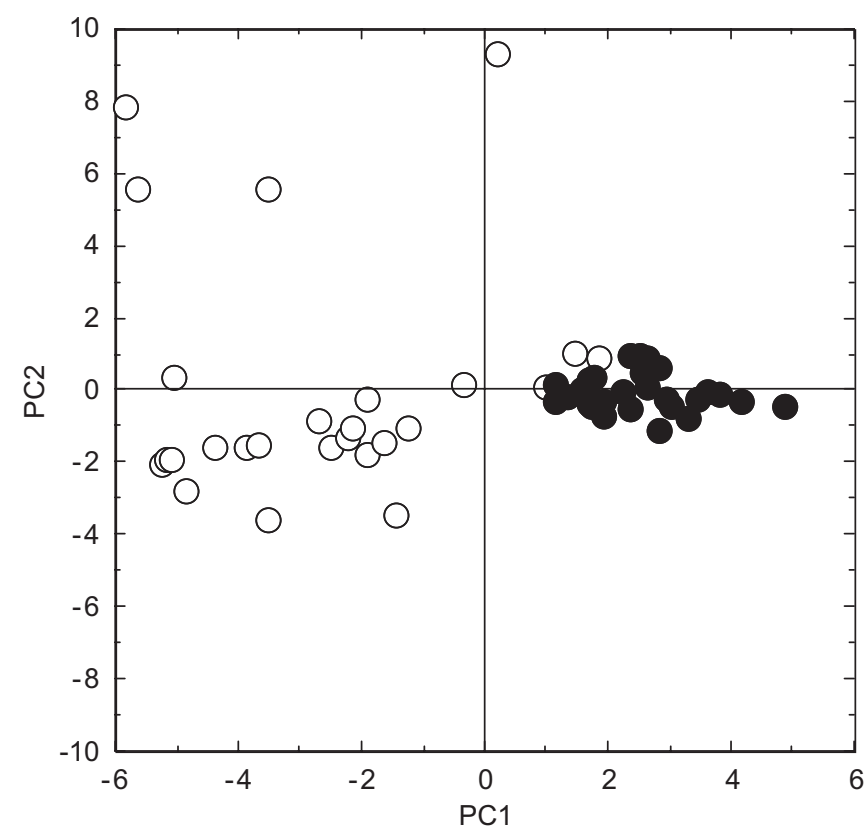

Fig. 2. Separation of male (closed circles) and female (open circles) Teleogryllus oceanicus cuticular hydrocarbon extracts based on the first two principal components (PC) extracted from the principal component analysis.

hydrocarbons have been found in three species of Acrididae (Appendix). Indeed, there are also numerous examples of species in other taxa where there appears to be no sex specificity of cuticular hydrocarbons (Appendix). A lack of sexual dimorphism in some species could simply reflect methodological limitations. For example, most studies use gas chromatography retention times to analyse difference between the sexes, but there are many aspects of variation in hydrocarbon composition that are not 
Table 3

Correlations between relative concentrations of cuticular hydrocarbon peaks and the five components extracted from the principal components analysis

\begin{tabular}{|c|c|c|c|c|c|c|}
\hline \multirow[t]{2}{*}{ Peak } & \multirow[t]{2}{*}{ Retention time } & \multicolumn{5}{|c|}{ Principal component } \\
\hline & & 1 & 2 & 3 & 4 & 5 \\
\hline 1 & 20.33 & -0.12 & 0.38 & 0.15 & 0.07 & 0.03 \\
\hline 2 & 20.66 & -0.12 & 0.38 & 0.13 & 0.03 & 0.05 \\
\hline 3 & 20.84 & -0.08 & 0.39 & 0.17 & 0.08 & -0.03 \\
\hline 4 & 21.37 & 0.24 & 0.15 & 0.08 & 0.14 & -0.29 \\
\hline 6 & 22.02 & 0.03 & 0.11 & 0.21 & 0.63 & 0.10 \\
\hline 7 & 22.08 & 0.21 & 0.01 & -0.15 & 0.13 & 0.48 \\
\hline 8 & 22.34 & -0.16 & 0.32 & 0.10 & 0.01 & 0.02 \\
\hline 9 & 22.43 & 0.26 & 0.13 & 0.01 & -0.08 & -0.08 \\
\hline 10 & 22.55 & 0.03 & 0.33 & 0.04 & 0.02 & -0.15 \\
\hline 11 & 22.65 & 0.29 & 0.08 & -0.05 & -0.01 & 0.10 \\
\hline 12 & 22.77 & 0.30 & 0.06 & -0.09 & -0.02 & 0.03 \\
\hline 13 & 22.89 & 0.28 & 0.09 & -0.15 & -0.11 & 0.02 \\
\hline 14 & 23.68 & -0.20 & -0.24 & 0.13 & 0.27 & -0.15 \\
\hline 15 & 23.75 & 0.15 & -0.01 & 0.01 & 0.29 & 0.53 \\
\hline 16 & 23.95 & -0.18 & -0.26 & 0.23 & 0.09 & 0.07 \\
\hline 17 & 24.09 & 0.27 & 0.07 & -0.05 & 0.14 & -0.06 \\
\hline 18 & 24.42 & -0.19 & 0.16 & 0.34 & -0.19 & 0.20 \\
\hline 19 & 24.6 & 0.21 & 0.08 & 0.09 & 0.15 & -0.43 \\
\hline 20 & 24.82 & 0.23 & 0.00 & 0.36 & -0.01 & 0.17 \\
\hline 21 & 24.96 & 0.23 & -0.19 & 0.30 & 0.09 & -0.01 \\
\hline 22 & 25.14 & 0.26 & -0.17 & 0.20 & 0.00 & -0.09 \\
\hline 23 & 25.29 & 0.23 & -0.09 & 0.34 & -0.11 & -0.15 \\
\hline 24 & 27.19 & -0.16 & -0.13 & -0.16 & 0.50 & -0.19 \\
\hline 25 & 28.36 & -0.07 & -0.19 & 0.47 & -0.16 & 0.06 \\
\hline
\end{tabular}

Peaks that contribute significant amounts to the principal components are in bold.

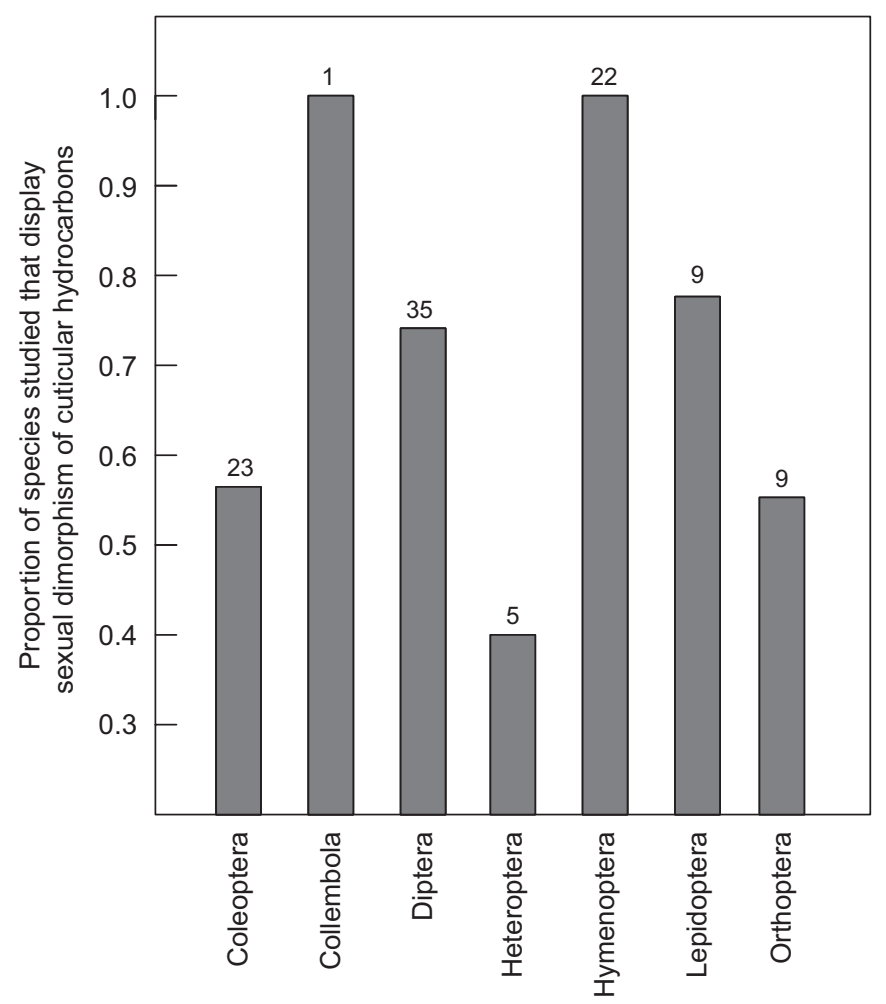

Fig. 3. The proportion of species investigated that display sexual dimorphism in cuticular hydrocarbons. Species are grouped by order, and the total number of species investigated in each order for this trait is shown above the bars. See Appendix for more details.

revealed by this approach (i.e. the position of double bonds or an enantiomeric composition of hydrocarbons). Furthermore, differences in cuticular hydrocarbons between the sexes can change in relation to a number of biological states, such as age and reproductive status; differences between sexes can be more marked in older than younger individuals (Caputo et al., 2005), and mated females often produce hydrocarbons that are the same as the major hydrocarbon component of mature males (Andersson et al., 2000; Kukuk, 1985; Scott, 1986; Sreng, 2006). In studies using field-collected samples, it is often difficult to know the biological state of specimens. Despite these methodological limitations, it is clear from our review that differences between the sexes are not directly linked to phylogeny. For example, three members of the melanogaster subgroup of Drosophila species display marked sexual dimorphism in cuticular hydrocarbons, while five other species in the group do not (Cobb and Jallon, 1990). Moreover, some species of Drosophila display qualitative differences between the sexes (Cobb and Jallon, 1990), while males and females of other species contain the same hydrocarbons, but differ in the relative abundance of compounds (Blows and Allan, 1998). This divergence in the presence/absence of sexual dimorphism across taxa suggests that sexual selection may be a strong driving force in the evolution of this trait.

Sexual selection could drive differentiation of cuticular hydrocarbons, if the chemical composition of the cuticle is used as a contact pheromonal signal in mate choice. Confirmation of the use of cuticular hydrocarbons in mate choice comes from a large number of studies that have demonstrated that particular compounds produced by one sex stimulate sexual behaviour of the other, or that gender specific ratios of cuticular hydrocarbons can influence mate choice (Appendix). Furthermore, most sexually selected traits related to mate choice, show delayed maturation (Delhey et al., 2007), and a number of studies have demonstrated that differences in the cuticular hydrocarbons between sexes can be more marked in older than younger individuals (Caputo et al., 2005; Mpuru et al., 2001; Brown et al., 1992). But perhaps the most convincing evidence that sexual selection can drive cuticular hydrocarbon evolution comes from studies of Drosophila, where cuticular hydrocarbons have been formally examined in this context. Chenoweth and Blows (2005) reported strong directional sexual selection on male and female cuticular hydrocarbons in D. serrata, but the strength of sexual selection differed between the sexes. In this species, the evolution of sexual dimorphism appears to have been achieved by sex-limited expression of traits controlled by genes on the $\mathrm{X}$ chromosome (Chenoweth and Blows, 2003).

Although there is strong evidence to suggest that sexual selection drives the evolution of sexual dimorphism in cuticular hydrocarbons, consideration must also be given to the possibility that in some species this sexual dimorphism could be a result of environmental selection, and have no associated signalling value. For example, the original function of cuticular hydrocarbons is thought to be protection against desiccation, so changes in cuticular hydrocarbon composition between the sexes could reflect divergence in microhabitat preferences of males and females. Certainly, some structural features of cuticular hydrocarbons such as chain length, degree and position of unsaturation and of methyl branching, are associated with different rates of water loss (Gibbs, 1998). Furthermore, experimental manipulation of temperatures during early imaginal life of Drosophila melanogaster has shown that changes in temperature can affect the ontogeny of sexually dimorphic cuticular hydrocarbons (Savarit and Ferveur, 2002). Although it seems unlikely that environmental selection influences the divergence of male and female cuticular hydrocarbons for species such as T. oceanicus, where there does not appear to be any gender lifestyle differences, this type of selection process should be considered for species with sex-dependent habitat preferences. 
It is also possible that selective processes act on other phenotypic variances that inadvertently effect the composition of the cuticle. Learning more about the biosynthesis of cuticular hydrocarbons will certainly aid in distinguishing between direct and indirect selection within each species. For example, are the hydrocarbons in question influenced by diet, or are they synthesized in situ? Certainly, in some species, hydrocarbon synthesis is related to food intake, while in other species, critical enzymes involved in cuticular hydrocarbon biosynthesis have been isolated, and several sex determination genes clearly influence cuticular hydrocarbon profiles (see Howard and Blomquist, 2005 for review). Ultimately it could be a combination of interacting selection processes that has the greatest influence on the level of cuticular hydrocarbon expression in each sex. Certainly, in Drosophila, the interaction between natural and sexual selection has a greater influence on the evolution of mate recognition via cuticular hydrocarbon profiles than either process in isolation (Blows, 2002).

Whatever the evolutionary processes that led to sexually dimorphic cuticular hydrocarbons in such a wide range of insect species, it is clear from the literature that female specific pheromones stimulate male courtship behaviour (Appendix), while male specific cuticular pheromones can influence a female's propensity to mate (Grillet et al., 2006). For example, in the cricket G. bimaculatus, males are known to display avoidance or aggressive behaviour to male cuticular hydrocarbons (Nagamoto et al., 2005), but courtship behaviour to female hydrocarbons (Tregenza and Wedell, 1997; Nagamoto et al., 2005). These behavioural responses by males to sex specific cuticular hydrocarbons may also be apparent in T. oceanicus, but have yet to be investigated.

\section{Acknowledgements}

Thanks to A. Reeder for providing access to the GCMS. This work was supported by funding from the Australian Research Council, the University of Western Australia, and the West Australian Centres of Excellence in Science and Innovation Program.

\section{Appendix. Insect species in which sexual dimorphism of cuticular hydrocarbons has been investigated}

\begin{tabular}{|c|c|c|c|c|c|}
\hline Order & Family & Species & Dimorphic & Stimulatory role & References \\
\hline \multirow[t]{23}{*}{ Coleoptera } & Cantharidae & Rhagonycha fulva & Yes & & Jacob (1978) \\
\hline & \multirow[t]{5}{*}{ Cerambycidae } & Anoplophora glabripennis & Yes & Yes & Zhang et al. (2003) \\
\hline & & Anoplophora malasiaca & Yes & Yes & Fukaya (2003), Fukaya et al. 2000 \\
\hline & & Megacyllene caryae & Yes & Yes & $\begin{array}{l}\text { Ginzel and Hanks (2003a), Ginzel et al. } \\
(2003 c)\end{array}$ \\
\hline & & Megacyllene robiniae & Yes & Yes & Ginzel et al. (2003c), Ginzel et al. (2006) \\
\hline & & Xylotrechus colonus & Yes & Yes & Ginzel et al. (2003b) \\
\hline & \multirow[t]{3}{*}{ Chrysomelidae } & Diabrotica barberi & Yes & & Golden et al. (1992) \\
\hline & & Diabrotica longicornis & Yes & & Golden et al. (1992) \\
\hline & & Leptinotarsa decemlineata & Yes & & Dubis et al. (1987) \\
\hline & \multirow[t]{11}{*}{ Curculionidae } & Caulophilus oryzae & No & & Howard and Perez-Lachaud (2002) \\
\hline & & Ips confusus & No & & Page et al. (1997) \\
\hline & & Ips cribricollis & No & & Page et al. (1997) \\
\hline & & Ips grandicollis & No & & Page et al. (1997) \\
\hline & & Ips hoppingi & No & & Page et al. (1997) \\
\hline & & Ips latidens & No & & Page et al. (1997) \\
\hline & & Ips lecontei & Yes & & Page et al. (1997) \\
\hline & & Ips montanus & No & & Page et al. (1997) \\
\hline & & Ips paraconfusus & No & & Page et al. (1997) \\
\hline & & Ips pini & No & & Page et al. (1997) \\
\hline & & Orthotomicus caelatus & No & & Page et al. (1997) \\
\hline & Scarabaeidae & Canthon cyanellus cyanellus & Yes & Yes & $\begin{array}{l}\text { Ortiz-Dominguez et al. (2006), Ortiz- } \\
\text { Dominguez et al. (2006) }\end{array}$ \\
\hline & Scolytidae & Hypothenemus hampei & Yes & & Howard and Inante (1996) \\
\hline & Staphylinidae & Aleochara curtula & Yes & Yes & Peschke and Metzler (1987) \\
\hline Collembola & Hypogastruridae & Schoettella ununguiculata & Yes & & Porco et al. (2004) \\
\hline \multirow[t]{22}{*}{ Diptera } & \multirow[t]{4}{*}{ Calliphoridae } & Chrysomya bezziana & Yes & & Brown et al. (1998), Brown et al. (1992) \\
\hline & & Cochliomyia hominivora & Yes & Yes & Mackley and Broce (1981), Pomonis (1989) \\
\hline & & Lucilia cuprina & Yes & & Goodrich (1970) \\
\hline & & Phormia regina & No & & Stoffolano et al. (1997 \\
\hline & \multirow[t]{5}{*}{ Culicidae } & Aedes aegypti & Yes & & Horne and Priestman (2002 \\
\hline & & Aedes hendersoni & No & & Pappas et al. (1994 \\
\hline & & Aedes triseriatus & No & & Pappas et al. (1994 \\
\hline & & Anopheles gambiae & Yes & & Caputo et al. (2005) \\
\hline & & Culex quinquefasciatus & Yes & & Chen et al. (1990) \\
\hline & \multirow[t]{13}{*}{ Drosophilidae } & Drosophila birchii & Yes & Yes & Blows and Allan (1998) \\
\hline & & Drosophila erecta & Yes & Yes & Cobb and Jallon (1990) \\
\hline & & Drosophila malenogaster & Yes & Yes & Cobb et al. (1990), Coyne et al. (1994) \\
\hline & & Drosophila mauritiana & No & & Cobb et al. (1990), Coyne et al. (1994) \\
\hline & & Drosophila orena & No & & Jallon and David (1987) \\
\hline & & Drosophila pallidosa & Yes & Yes & Nemoto et al. (1994) \\
\hline & & Drosophila pseudoobscura & No & & Toolson and Kupersimbron (1989) \\
\hline & & Drosophila sechellia & Yes & Yes & Cobb et al. (1990), Coyne et al. (1994) \\
\hline & & Drosophila serrata & Yes & Yes & Blows et al. (1998), Hine et al. (2002) \\
\hline & & Drosophila simulans & No & & Cobb et al. (1990), Coyne et al. (1994) \\
\hline & & Drosophila teissieri & No & & Cobb et al. (1990) \\
\hline & & Drosophila virilis & Yes & Yes & $\begin{array}{l}\text { Jackson and Bartelt (1986), Oguma et al. } \\
\text { (1992) }\end{array}$ \\
\hline & & Drosophila yakuba & No & & Cobb et al. (1990) \\
\hline
\end{tabular}




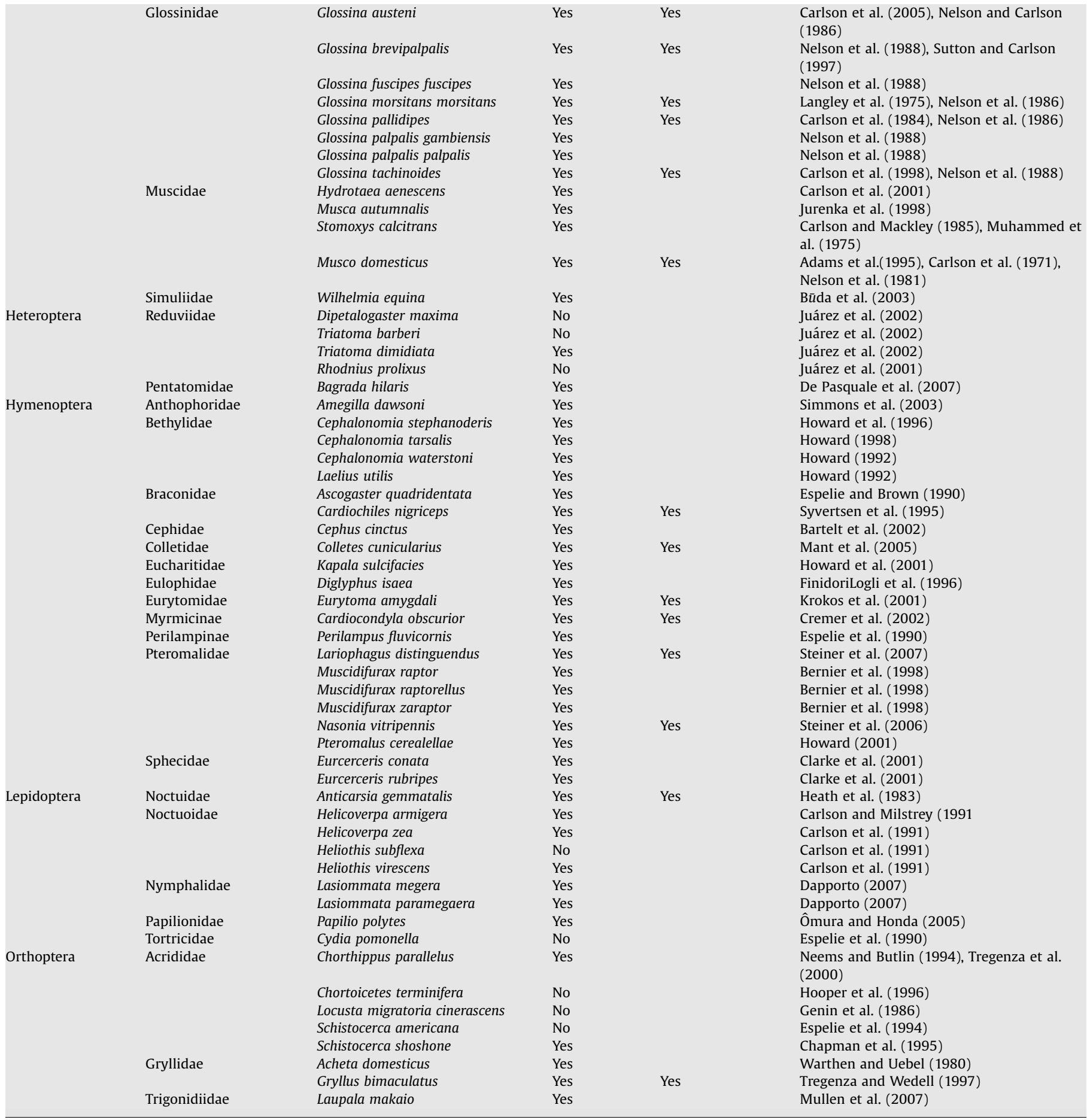

References

Adams, T.S., Nelson, D.R., Fatland, C.L., 1995. Effects of methylalkanes on male house fly, Musca domestica, sexual behavior. Journal of Insect Physiology $41,443-449$. Bartelt, R.J., Cosse, L.A., Petroski, R.J., Weaver, D.K., 2002. Cuticular hydrocarbons and novel alkenediol diacetates from wheat stem sawfly (Cephus cinctus): natural oxidation to pheromone components. Journal of Chemical Ecology 28, 385-405.

Bernier, U.R., Carlson, D.A., Geden, C.J., 1998. Gas chromatography mass spectrometry analysis of the cuticular hydrocarbons from parasitic wasps of the genus Muscidifurax. Journal of the American Society for Mass Spectrometry 9, 320-332.

Blows, M.W., Allan, R.A., 1998. Levels of mate recognition within and between two Drosophila species and their hybrids. American Naturalist 152, 826-837.

Brown, W.V., Morton, R., Spradbery, J.P., 1992. Cuticular hydrocarbons of the Old-world screwworm fly, Chrysomya bezziana Villeneuve (Diptera, Calliphoridae)-chemical characterization and quantification by age and sex. Comparative Biochemistry and Physiology B 101, 665-671.

Brown, W.V., Morton, R., Lacey, M.J., Spradbery, J.P., Mahon, R.J., 1998. Identification of the geographical source of adults of the Old World screwworm fly, Chrysomya bezziana Villeneuve (Diptera: Calliphoridae), by multivariate analysis of cuticular hydrocarbons. Comparative Biochemistry and Physiology B 119, 391-399.

Būda, V., Mozūraitis, R., Jonušaite, V., 2003. Chemical ecology of blackflies: sexual dimorphism in cuticular washes of Wilhelmia equina (L.) (Diptera: Simuliidae). Ekologija 1, 81-88. Caputo, B., Dani, F.R., Horne, G.L., Petrarca, V., Turillazzi, S., Coluzzi, M., Priestman, A.A., Della Torre, A., 2005. Identification and composition of cuticular hydrocarbons of the major Afrotropical malaria vector Anopheles gambiae (Diptera: Culicidae): analysis of sexual dimorphism and age-related changes. Journal of Mass Spectrometry 40, 1595-1604.

Carlson, D.A., Mackley, J.W., 1985. Polyunsaturated hydrocarbons in the stable fly. Journal of Chemical Ecology 11, 1485-1496.

Carlson, D.A., Milstrey, S.K., 1991. Alkanes of four related moth species, Helicoverpa and Heliothis. Archives of Insect Biochemistry and Physiology 16, 165-175.

Carlson, D.A., Mayer, M.S., Silhacek, D.L., James, J.D., Beroza, M., Bierl, B.A., 1971. Sex attractant pheromone of the house fly: isolation, identification and synthesis. Science 174, 76-78. 


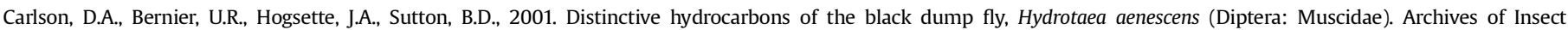
Biochemistry and Physiology 48, 167-178.

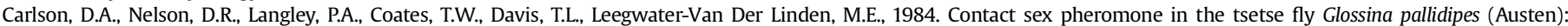
identification and synthesis. Journal of Chemical Ecology 10, 429-450.

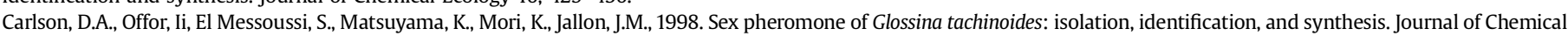
Ecology 24, 1563-1575.

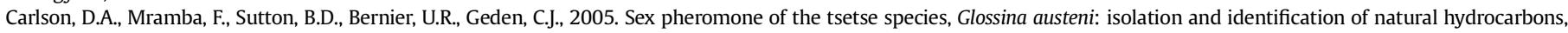
and bioassay of synthesized compounds. Medical and Veterinary Entomology 19, 470-479.

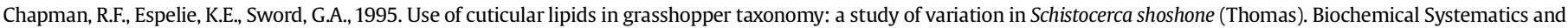
Ecology 23, 383-398.

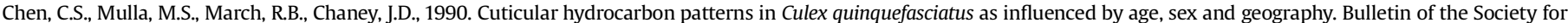
Vector Ecology 15, 129-139.

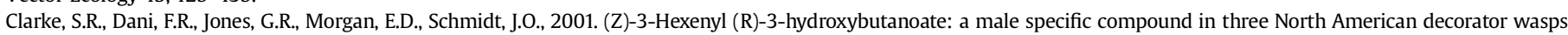
Eucerceris rubripes, E. conata and E. tricolor. Journal of Chemical Ecology 27, 1437-1447.

Cobb, M., Jallon, J.-M., 1990. Pheromones, mate recognition and courtship stimulation in the Drosophila melanogaster species sub-group. Animal Behaviour 39, $1058-1067$.

Coyne, J.A., Crittenden, A.P., Mah, K., 1994. Genetics of a pheromonal difference contributing to reproductive isolation in Drosophila. Science 265, $1461-1464$.

Cremer, S., Sledge, M.F., Heinze, J., 2002. Chemical mimicry: male ants disguised by the queen's bouquet. Nature 419, $897-897$.

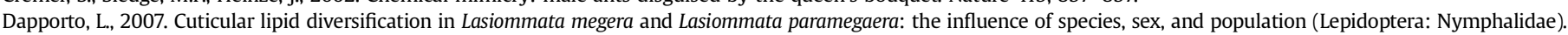
Biological Journal of the Linnean Society 91, 703-710.

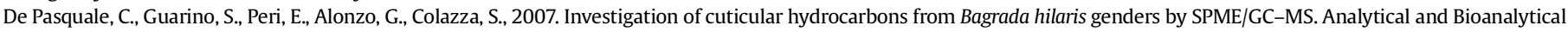
Chemistry 389, 1259-1265.

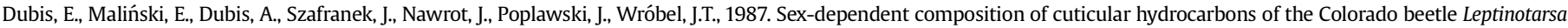
decemlineata Say. Comparative Biochemistry and Physiology 87A, 839-843.

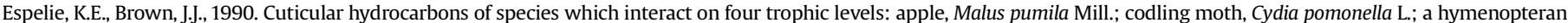
parasitoid, Ascogaster quadridentata Wesmael; and a hyperparasite, Perilampus fulvicornis Ashmead. Comparative Biochemistry and Physiology 95B, $131-136$.

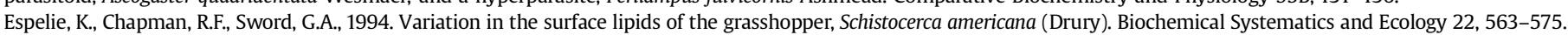

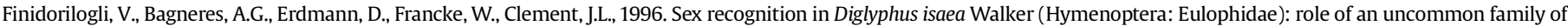
behaviorally active compounds. Journal of Chemical Ecology 22, 2063-2079.

Fukaya, M., 2003. Recent advances in sex pheromone studies on the white-spotted longicorn beetle, Anoplophora malasiaca. Japan Agricultural Research Quarterly 37, 83-88.

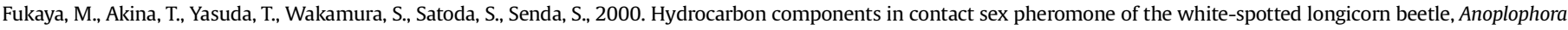
malasiaca (Thomson) (Coleoptera: Cerambycidae) and pheromonal activity of synthetic hydrocarbons. Entomological Science 3, 211-218.

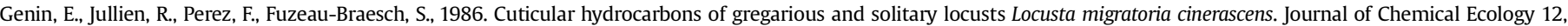
1213-1238.

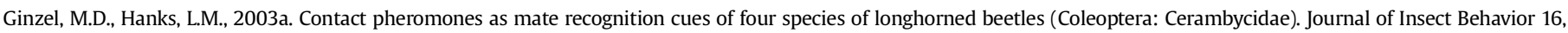
181-187.

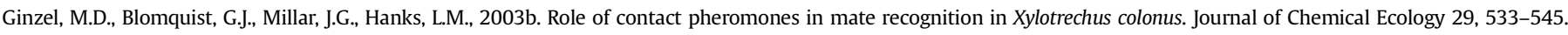
Ginzel, M.D., Millar, J.G., Hanks, L.M., 2003c. (Z)-9-Pentacosene-contact sex pheromone of the locust borer, Megacyllene robiniae. Chemoecology 13, 135-141.

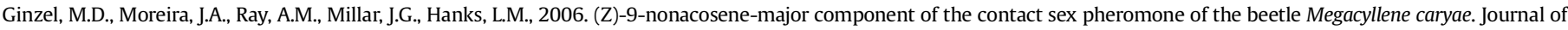
Chemical Ecology 32, 435-451.

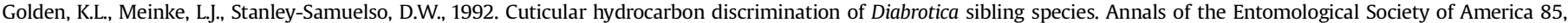
561-570.

Goodrich, B.S., 1970. Cuticular lipids of adults and puparia of the Australian sheep blowfly Lucilia cuprina (Wied.). Journal of Lipid Research 11, 1-6.

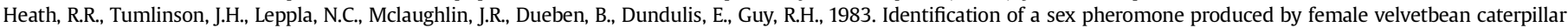
moth, Lepidoptera, Noctuidae. Journal of Chemical Ecology 9, 645-656.

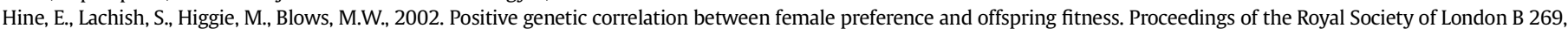
2215-2219.

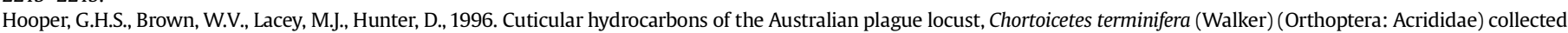
from widely separated geographical locations. Australian Journal of Entomology 35, 257-262.

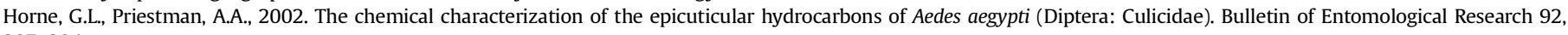
287-294.

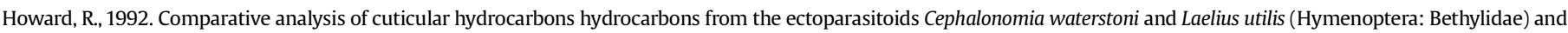

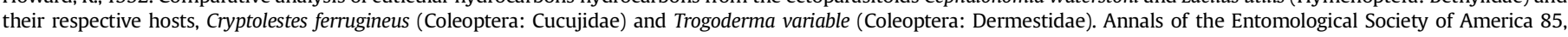
317-325.

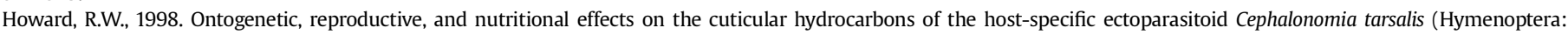
Bethylidae). Annals of the Entomological Society of America 91, 101-112.

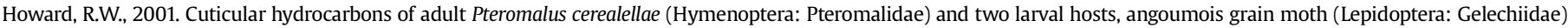
and cowpea weevil (Coleptera: Bruchidae). Annals of the Entomological Society of America 94, 152-158.

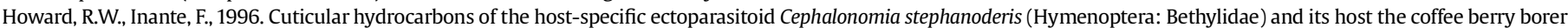
(Coleoptera: Scolytidae). Annals of the Entomological Society of America 89, 700-709.

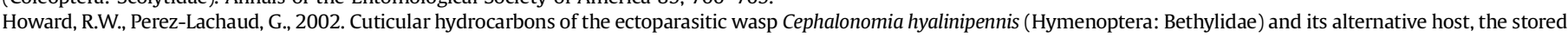
product pest Caulophilus oryzae (Coleoptera: Curculionidae). Archives of Insect Biochemistry and Physiology 50, 75-84.

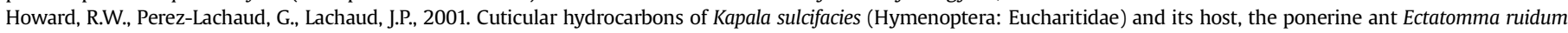
(Hymenoptera: Formicidae). Annals of the Entomological Society of America 94, 707-716.

Jackson, L.L., Bartelt, R.J., 1986. Cuticular hydrocarbons of Drosophila virilis: comparison by age and sex. Insect Biochemistry 16, 433-439.

Jacob, J., 1978. Sex-dependent composition of cuticular lipids from the beetle Rhagonycha fulva. Hoppe-Seyler's Z. Physiological Chemistry 359, 653-656.

Jallon, J.M., David, J.R., 1987. Variations in cuticular hydrocarbons among the eight species of Drosophila malenogaster subgroup. Evolution 41, $294-302$.

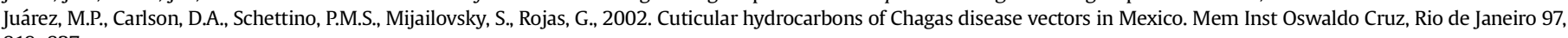
819-827.

Juárez, P., Blomquist, G.J., Schofield, C.J., 2001. Hydrocarbons of Rhodnius prolixus, a Chagas disease vector. Comparative Biochemistry and Physiology 129B, 733-746.

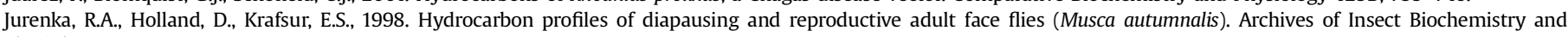
Physiology 37, 206-214.

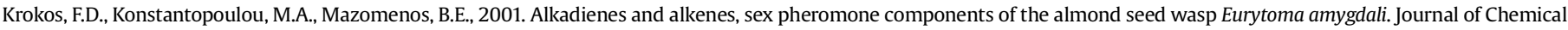
Ecology 27, 2169-2181.

Langley, P.A., Pimley, R.W., Carlson, D.A., 1975. Sex recognition pheromone of the tsetse fly. Nature 254, 51-53.

Mackley, J.W., Broce, A.B., 1981. Evidence of a female sex recognition pheromone in the screwworm fly. Environmental Entomology $10,406-408$.

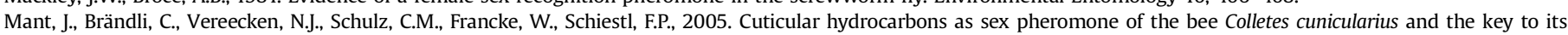
mimicry by the sexually deceptive orchid, Ophrys exaltata. Journal of Chemical Ecology 31, 1765-1787.

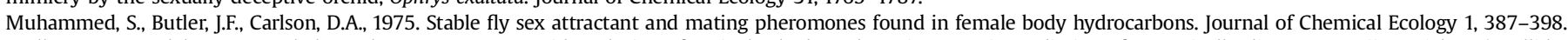

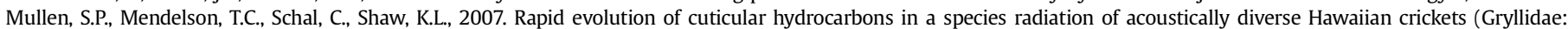

Trigonidiinae: Laupala). Evolution 61, 223-231. 


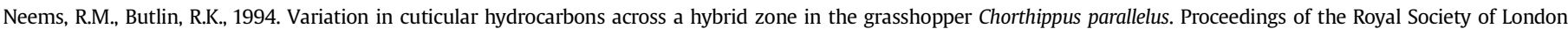
Series B 257, 135-140.

Nelson, D.R., Carlson, D.A., 1986. Cuticular hydrocarbons of the tsetse flies Glossina morsitans morsitans, G. austeni and G. pallidipes. Insect Biochemistry 16, 403-416.

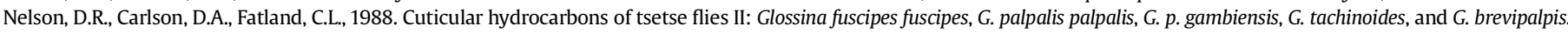
Journal of Chemical Ecology 14, 963-987.

Nelson, D.R., Dillwith, J.W., Blomquist, G.J., 1981. Cuticular hydrocarbons of the house fly, Musca domestica. Insect Biochemistry 11, 187-197.

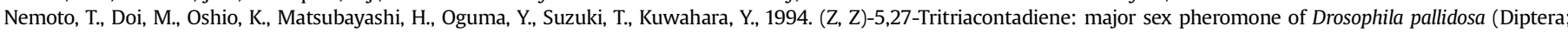
Drosophilidae). Journal of Chemical Ecology 20, 3029-3037.

Oguma, Y., Nemoto, T., Kuwahara, Y., 1992. (Z)-11-Pentacosene is the major sex pheromone component in Drosophila virilis (Diptera). Chemoecology 3, 60-64.

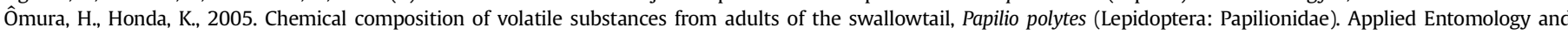
Zoology 40, 421-427.

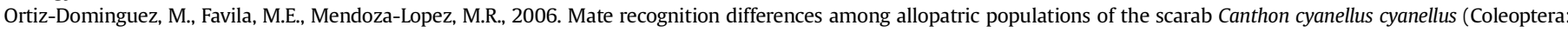
Scarabaeidae). Annals of the Entomological Society of America 99, 1248-1256.

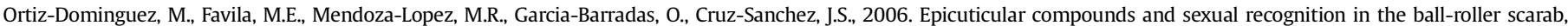
Canthon cyanellus cyanellus. Entomologia Experimentalis et Applicata 119, $23-27$.

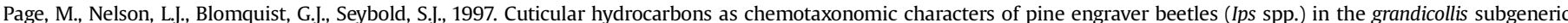
group. Journal of Chemical Ecology 23, 1053-1099.

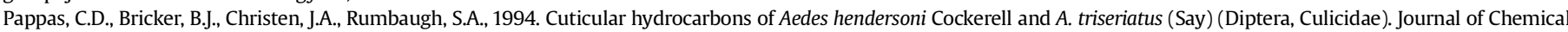
Ecology 20, 1121-1136.

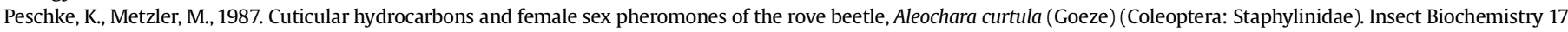
167-178.

Pomonis, J.G., 1989. Cuticular hydrocarbons of the screwworm, Cochliomyia hominivorox (Diptera: Calliphoridae). Journal of Chemical Ecology 15, 2301-2317.

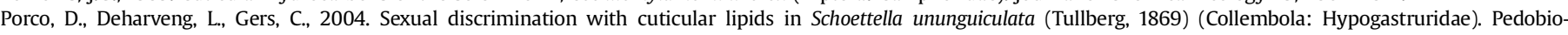
logia 48, 581-583.

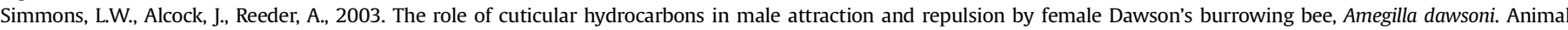
Behaviour 66, 677-685.

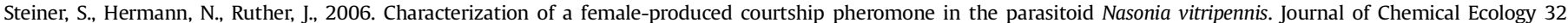
1687-1702.

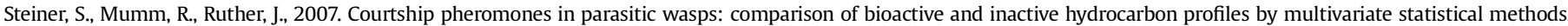
Journal of Chemical Ecology 33, 825-838.

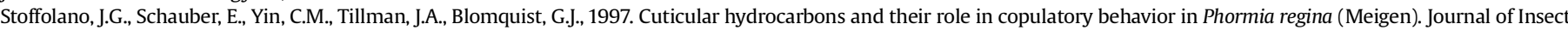
Physiology 43, 1065-1076.

Sutton, B.D., Carlson, D.A., 1997. Cuticular hydrocarbons of Glossina, III: subgenera Glossina and Nemorhina. Journal of Chemical Ecology 23, $1291-1320$.

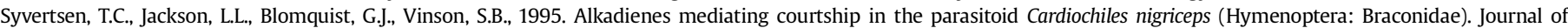
Chemical Ecology 21, 1971-1989.

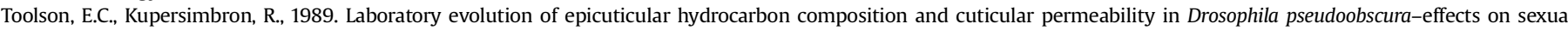
dimorphism and thermal acclimation ability. Evolution 43, 468-473.

Tregenza, T., Wedell, N., 1997. Definitive evidence for cuticular pheromones in a cricket. Animal Behaviour 54, 979-984.

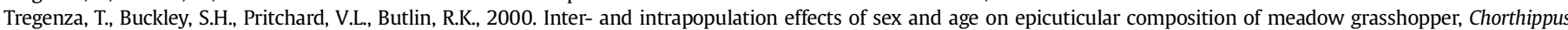
parallelus. Journal of Chemical Ecology 26, 257-278.

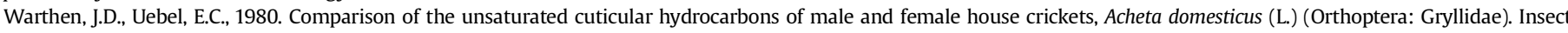
Biochemistry 10, 435-439.

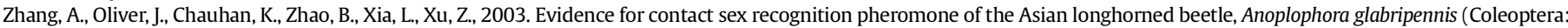
Cerambycidae). Naturwissenschaften 90, 410-413.

\section{References}

Andersson, J., Borg-Karlson, A.K., Wiklund, C., 2000. Sexual cooperation and conflict in butterflies: a male-transferred anti-aphrodisiac reduces harassment of recently mated females. Proceedings of the Royal Society of London B 267, 1271-1275.

Blomquist, G., Blailock, T., Scheetz, R., Jackson, L., 1976. Cuticular lipids of insectsVII. Cuticular hydrocarbons of the crickets Acheta domesticus, Gryllus pennsylvanicus and Nemobius fasciatus. Comparative Biochemistry and Physiology 54B, 381-386.

Blows, M.W., 2002. Interaction between natural and sexual selection during the evolution of mate recognition. Proceedings of the Royal Society of London B 269, 1113-1118.

Blows, M.W., Allan, R.A., 1998. Levels of mate recognition within and between two Drosophila species and their hybrids. American Naturalist 152, 826-837.

Brown, W.V., Morton, R., Spradbery, J.P., 1992. Cuticular hydrocarbons of the Oldworld screwworm fly, Chrysomya bezziana Villeneuve (Diptera, Calliphoridae)-chemical characterization and quantification by age and sex. Comparative Biochemistry and Physiology B 101, 665-671.

Caputo, B., Dani, F.R., Horne, G.L., Petrarca, V., Turillazzi, S., Coluzzi, M., Priestman, A.A., Della Torre, A., 2005. Identification and composition of cuticular hydrocarbons of the major Afrotropical malaria vector Anopheles gambiae (Diptera: Culicidae): analysis of sexual dimorphism and age-related changes. Journal of Mass Spectrometry 40, 1595-1604.

Chenoweth, S.F., Blows, M.W., 2003. Signal trait sexual dimorphism and mutual sexual selection in Drosophila serrata. Evolution 57, 2326-2334.

Chenoweth, S.F., Blows, M.W., 2005. Contrasting mutual sexual selection on homologous signal traits in Drosophila serrata. American Naturalist 165, $281-289$.

Cobb, M., Jallon, J.-M., 1990. Pheromones, mate recognition and courtship stimulation in the Drosophila melanogaster species sub-group. Animal Behaviour 39, 1058-1067.

Delhey, K., Peters, A., Kempenaers, B., 2007. Cosmetic coloration in birds: occurrence, function, and evolution. American Naturalist 169, S145-S158.
Ferveur, J.F., 2005. Cuticular hydrocarbons: their evolution and roles in Drosophila pheromonal communication. Behavior Genetics 35, 279-295.

Gibbs, A.G., 1998. Water-proofing properties of cuticular lipids. American Zoologist 38, 471-482.

Grillet, M., Dartevelle, L., Ferveur, J.F., 2006. A Drosophila male pheromone affects female sexual receptivity. Proceedings of the Royal Society of London B 273 $315-323$.

Hoffmann, K.H., Dettner, K., Tomaschko, K.H., 2006. Chemical signals in insects and other arthropods: from molecular structure to physiological functions. Physiological and Biochemical Zoology 79, 344-356.

Howard, R.W., Blomquist, G.J., 2005. Ecological, behavioral, and biochemical aspects of insect hydrocarbons. Annual Review of Entomology 50, 371-393.

Ivy, T.M., Weddle, C.B., Sakaluk, S.K., 2005. Females use self-referent cues to avoid mating with previous mates. Proceedings of the Royal Society of London B 272, 2475-2478.

Kortet, R., Hedrick, A., 2005. The scent of dominance: female field crickets use odour to predict the outcome of male competition. Behavioural Ecology and Sociobiology 59, 77-83.

Kukuk, P., 1985. Evidence for an antiaphrodisiac in the sweat bee Lasioglossum zephyrum (Dialictus). Science 227, 656-657.

Mardia, K.V., Kent, J.T., Bibby, J.M., 1979. Multivariate Analysis. Academic Press, London.

Mpuru, S., Blomquist, G.J., Schal, C., Roux, M., Kuenzli, M., Dusticier, G., Clement J.L., Bagneres, A.G., 2001. Effect of age and sex on the production of internal and external hydrocarbons and pheromones in the housefly, Musca domestica. Insect Biochemistry and Molecular Biology 31, 139-155.

Nagamoto, J., Aonuma, H., Hisada, M., 2005. Discrimination of conspecific individuals via cuticular pheromones by males of the cricket Gryllus bimaculatus. Zoological Science 22, 1079-1088.

Neems, R.M., Butlin, R.K., 1995. Divergence in cuticular hydrocarbons between parapatric subspecies of the meadow grasshopper, Chorthippus parallelus (Orthoptera, Acrididae). Biological Journal of the Linnean Society 54, 139-149.

Norman, G.R., Streiner, D.L., 1994. Biostatistics: The Bare Essentials. Mosby, St Louis. 
Rundle, H.D., Chenoweth, S.F., Doughty, P., Blows, M.W., 2005. Divergent selection and the evolution of signal traits and mating preferences. Plos Biology 3, 1988-1995.

Savarit, F., Ferveur, J.F., 2002. Temperature affects the ontogeny of sexually dimorphic cuticular hydrocarbons in Drosophila melanogaster. Journal of Experimental Biology 205, 3241-3249.

Scott, D., 1986. Sexual mimicry regulates the attractiveness of mated Drosophila melanogaster females. Proceedings of the National Academy of Sciences USA 83, 8429-8433.

Simmons, L.W., 1991. Female choice and the relatedness of mates in the field cricket, Gryllus bimaculatus. Animal Behaviour 41, 493-501.
Simmons, L.W., Alcock, J., Reeder, A., 2003. The role of cuticular hydrocarbons in male attraction and repulsion by female Dawson's burrowing bee, Amegilla dawsoni. Animal Behaviour 66, 677-685.

Sreng, L., 2006. Cockroach tergal glands producing female sex attractant pheromones and male aphrodisiacs in particular in the subfamily Blaberinae (Blattaria: Blaberidae). European Journal of Entomology 103, 817-829.

Thomas, M.L., Simmons, L.W., 2007. Male crickets adjust the viability of their sperm in response to female mating status. American Naturalist 170, 190-195.

Tregenza, T., Wedell, N., 1997. Definitive evidence for cuticular pheromones in a cricket. Animal Behaviour 54, 979-984. 